\title{
Các yếu tố chất lượng dịch vụ hành chính công ảnh hưởng như thế nào đến sự hài lòng của người dân huyện Châu Phú, tỉnh An Giang?
}

\section{How do the quality dimensions of public administration services affect citizen satisfaction at Chauphu District, Angiang Province?}

\author{
Nguyễn Hữu Dũng ${ }^{1 *}$ \\ ${ }^{1}$ Trường Đại học Kinh tế Thành phố Hồ Chí Minh, Việt Nam \\ *Tác giả liên hệ, Email: nhdung@ueh.edu.vn
}

THÔNG TIN

DOI: $10.46223 / \mathrm{HCMCOUJS}$. econ.vi.16.1.1306.2021

Ngày nhận: 05/11/2020

Ngày nhận lại: 29/12/2020

Duyệt đăng: 04/01/2021

\section{Tù khóa:}

chất lượng dịch vụ hành chính công, SERVPERF, sự hài

lòng, tỉnh An Giang
Keywords:

public administration service quality, SERVPERF, satisfaction, An Giang Province
TÓM TẮT
Sự hài lòng của khách hàng là mục tiêu quan trọng, ảnh hưởng đến sự thành công và bền vững, của hầu hết các tổ chức cung ứng dịch vụ. Mục đích của nghiên cứu gồm: 1) xem xét chất lượng dịch vụ được cung cấp tại Bộ phận tiếp nhận và trả kết quả, thuộc UBND huyện Châu Phú, tỉnh An Giang; và 2) xác định các yếu tố chất lượng dịch vụ nào có ảnh hưởng quan trọng đến sự hài lòng của người dân. Nghiên cứu áp dụng phương pháp định lượng thông qua bảng khảo sát gồm 24 biến quan sát, thang đo Likert 5 mức độ, về đánh giá cảm nhận của 172 người dân ngay sau khi nhận kết quả các dịch vụ hành chính. Các kỹ thuật phân tích chính gồm phân tích khám phá yếu tố (EFA), hệ số Cronbach's Alpha, phân tích ANONA một chiều với kiểm định giá trị khác biệt nhỏ nhất có nghĩa (LSD), hồi quy bội, và các thống kê mô tả. Kết quả chỉ ra rằng 1) năm yếu tố của thang đo SERVPERF cấu thành một công cụ có giá trị để đo lường chất lượng dịch vụ trong bối cảnh huyện Châu Phú; 2) năm yếu tố của chất lượng dịch vụ, gồm Năng lực, cơ sở Vật chất, Tin cậy, Thái độ phục vụ, và Đồng cảm đều có ảnh hưởng mạnh và làm gia tăng sự hài lòng. Trong đó, yếu tố năng lực cán bộ tác động mạnh nhất. Kết quả nghiên cứu là thông tin nền tảng cho lãnh đạo huyện Châu Phú để cải thiện chất lượng dịch vụ và nâng cao sự hài lòng của người dân.

\section{ABSTRACT}

Customers' satisfaction is a vital goal, influencing the success and sustainability of almost all service organizations. The study's objectives are two-fold: 1) to examine the service quality provided at the Survive Unit of People's Committee of Chauphu district, Angiang Province; and 2) to identify the most important service quality dimensions that determine citizen satisfaction. The study adopts a quantitative technique employing a 26-item, seven-point Likert-scaled questionnaire to elicit the perceptions of 172 persons right after receiving service performance results at the Unit. Analysis was done by using exploratory factor analysis (EFA), Cronbach's Alpha, one-way analysis of variance with the least 
significant difference (LSD) test, multiple regression, and standard descriptive statistics. Results indicate that (1) the five dimensions of SERVPERF represent a valid instrument to measure municipal service quality in Chauphu setting; and (2) all five service quality dimensions, namely Assurance, Tangibles, Reliability, Responsiveness and Empathy have significantly strong and positive on citizen satisfaction. Among the fives, Assurance showed to be the most important factor. The findings can be used as a benchmarking guide for Chau Phu district officials to improve the crucial quality attributes and enhance citizen satisfaction.

\section{Giới thiệu vấn đề nghiên cứu}

Cung cấp dịch vụ có chất lượng được xem là một trong những chiến lược quan trọng cho sự thành công và bền vững của các tổ chức công hoặc tư nhân (Parasuraman, Zeithaml, \& Berry, 1985; Zeithaml, Bitner, \& Gremler, 2009). Các tổ chức công hiện nay đang đối diện trước sức ép nhu cầu ngày càng cao về cung ứng những dịch vụ công có chất lượng và hiệu quả của người dân trong xã hội. Dịch vụ công là một cấu thành trong các hoạt động không thể thiếu được trong điều hành của chính phủ tại tất cả các quốc gia trên thế giới nhằm đạt được những mục tiêu phát triển kinh tế, xã hội và con người (Ramseook-Munhurrun, Lukea-Bhiwajee, \& Naidoo, 2010). Khi những dịch vụ công được cung cấp kém hiệu quả thì nó không những làm suy yếu quyền lực của chính phủ trong việc thực thi các chính sách mà còn gây ảnh hưởng nghiêm trọng đến sự ổn định của chính phủ. Dịch vụ công được cung ứng từ các tổ chức công như dịch vụ giáo dục, y tế, hoặc các tổ chức khác được sự ủy quyền của nhà nước.

Dịch vụ hành chính công là một bộ phận trong số các dịch vụ công. Dịch vụ hành chính công trong nghiên cứu này là những hoạt động phục vụ các quyền và nghĩa vụ cơ bản của các tổ chức và công dân không vì lợi nhuận, do các cơ quan hành chính nhà nước thực hiện dựa vào thẩm quyền hành chính - pháp lý của Nhà nước. Thực hiện các quy định của Nghị định số 61/2018/NĐCP ngày 23/4/2018 của Chính phủ về thực hiện cơ chế một cửa, một cửa liên thông trong giải quyết thủ tục hành chính (TTHC), việc cung cấp các dịch vụ hành chính công tại các địa phương đã có những cải thiện đáng kể, thu được nhiều kết quả khả quan, giảm bớt sự phiền hà đối với người dân và doanh nghiệp, trong đó có chính quyền địa phương huyện Châu Phú tỉnh An Giang. Mặc dù công tác cải cách hành chính tại huyện, được đánh giá là có hiệu quả, quá trình thực hiện vẫn còn bộc lộ một số nhược điểm mà nguyên nhân chủ yếu là do năng lực, nhận thức của cán bộ trực tiếp giải quyết TTHC, cách thức tổ chức thực hiện chưa thực sự tốt như mong đợi, và thiếu các đánh giá định lượng về chất lượng cung ứng dịch vụ hành chính công. Trên cơ sở này, nghiên cứu được thực hiện nhằm mục đích xác định các yếu tố cấu thành của chất lượng dịch vụ và xem xét ảnh hưởng của chúng như thế nào đến sự hài lòng của người dân về kết quả dịch vụ tại Bộ phận tiếp nhận và trả kết quả thuộc UBND huyện Châu Phú tỉnh An Giang.

\section{Cơ sở lý thuyết và thực tiễn}

\subsection{Cơ sở lý luận về chất lự̛ng dịch vụ và sụ hài lòng khách hàng}

Chất lượng dịch vụ theo đánh giá cảm nhận của khách hàng (hoặc công dân trong trường hợp dịch vụ công) là một thành phần quan trọng trong nhận thức của khách hàng, vì nó là tiền đề của sự thỏa mãn (hài lòng). Nhận thức là tiến trình quan sát, sắp xếp đánh giá, nhận xét sau cùng của con người qua những lần trải nghiệm, quan sát hiện tượng, hoặc xử lý thông tin. Mặc dù, nhà cung cấp có thể thực hiện các hoạt động dịch vụ tốt nhất theo khả năng của họ, nhưng khách hàng không nhìn nhận những điều đó là có chất lượng tốt, thì tất cả cũng vô nghĩa. Vì thế, những nhà 
cung cấp dịch vụ cần hiểu rõ khách hàng nhận thức như thế nào là dịch vụ có chất lượng và đạt được cảm giác sảng khoái; những thành phần của chất lượng dịch vụ và sự hài lòng để tạo dựng sự thay đổi trong nhận thức của khách hàng (Dutta \& Dutta, 2009). Dựa trên giả định rằng khách hàng chỉ quan tâm về chất lượng nhận được thì chất lượng dịch vụ được hiểu là sự đánh giá sau cùng của khách hàng về mức độ tuyệt vời của dịch vụ và tổ chức cung cấp (Schneider \& White, 2004).

Kỳ vong của khách hàng là những mong muốn khách hàng cần đạt được từ sản phẩm dịch vụ trước khi được cung cấp. Tuy nhiên, những kỳ vọng này thì hầu như khác biệt với những gì mà khách hàng nhận được sau khi đã sử dụng dịch vụ. Khi dịch vụ làm khách hàng thỏa mãn (hài lòng), sẽ giúp nâng cao chất lượng cuộc sống của họ, và họ sẽ mong muốn dịch vụ được cung ứng nhanh hơn và chất lượng hơn. Nói cách khác thì chất lượng dịch vụ là sự so sánh chủ quan của khách hàng giữa giữa nhận thức về chất lượng đạt được và kỳ vọng về chất lượng trước khi sử dụng dịch vụ. Nếu kỳ vọng và nhận thức của khách hàng bằng nhau thì khách hàng được xem là hài lòng với dịch vụ được cung cấp (Parasuraman et al., 1985; Parasuraman, Zeithaml, \& Bitner, 1988).

Sự hài lòng của khách hàng không nhất thiết đồng nghĩa với chất lượng dịch vụ. Nhận thức của khách hàng về chất lượng dịch vụ ảnh hưởng đến ý định và hành vi của họ trong tương lai, và là một trong những yếu tố ảnh hưởng đến sự hài lòng (Zeithaml et al., 2009). Chất lượng dịch vụ là một biểu hiện của thái độ, đánh giá tổng thể sau cùng, còn hài lòng là một cảm giác. Sự khác biệt giữa 2 khái niệm bao gồm: a) Các khía cạnh của đánh giá về chất lượng tương đối cụ thể cho dù chúng là những tín hiệu hoặc là những thuộc tính; ngược lại mức độ hài lòng có thể là kết quả của bất kỳ khía cạnh nào, có liên quan đến chất lượng hay không; b) Điểm thứ hai là nhận thức về chất lượng không đòi hỏi sự từng trải về dịch vụ hoặc nhà cung cấp, trái lại phải có trải nghiệm tiêu dùng mới biết hài lòng như thế nào; c) Điểm thứ ba là khía cạnh chất lượng chỉ gồm vài khái niệm tiền đề về sản phẩm dịch vụ để đánh giá, còn sự hài lòng bị chi phối bởi nhiều tiến trình nhận thức và cảm xúc để có đánh giá sau cùng. (Cronin \& Taylor, 1992). Rất nhiều nghiên cứu khẳng định rằng chất lượng dịch vụ, bên cạnh các yếu tố như đặc điểm cá nhân, giá cả, mức tiện nghi và hiện đại, là yếu tố chính ảnh hưởng đến sự hài lòng (Dimitriades \& Maroudas, 2007; Rust \& Oliver, 1994).

\subsection{Mô hình đo luò̀ng chất luọng dịch vụ SERVQUAL và SERVPERF}

Những lý luận, khái niệm khác nhau về chất lượng dịch vụ và sự hài lòng dẫn đến việc hình thành các mô hình hoặc thang đo chất lượng dịch vụ và sự hài lòng. Để đo lường mối quan hệ giữa chất lượng dịch vụ và sự hài lòng của khách hàng, mô hình SERVQUAL (Parasuraman et al., 1985, 1988) đã được nhiều sự đồng tình và ứng dụng rộng rải trong rất nhiều nghiên cứu về vấn đề này. Thang đo Likert được áp dụng với 22 biến quan sát của 5 khía cạnh chất lượng dịch vụ, để đo lường cả giá trị kỳ vọng và giá trị cảm nhận kết quả của khách hàng về dịch vụ.

Tuy nhiên, một số tác giả khác có những tranh luận về khía cạnh khái niệm và thực tiễn của mô hình SERVQUAL là các lý thuyết về tâm lý, thống kê và kinh tế không hỗ trợ mạnh cho lý lẽ của mô hình (Cronin \& Taylor, 1992). Việc sử dụng khoảng cách giữa giá trị kỳ vọng và kết quả dịch vụ để đo lường chất lượng dịch vụ là chưa được phù hợp bởi vì khái niệm chất lượng dịch vụ được dựa trên thái độ của khách hàng. Trong khi đó sự hài lòng của khách hàng thì dựa trên sự việc đã xảy ra để so sánh sự khác biệt giữa kỳ vọng và kết quả. Như vậy, nếu chất lượng dịch vụ được dựa trên thái độ của khách hàng, thì chất lượng dịch vụ cần được đánh giá theo những nhận thức về kết quả thực hiện các đặc trưng của dịch vụ cụ thể. Vì thế, nhiều tác giả đồng thuận đề xuất rằng chất lượng dịch vụ nên được đánh giá trên khía cạnh thực hiện dịch vụ, SERVPERF, và hàm ý rằng những nhận thức của khách hàng là đủ để xác định chất lượng dịch vụ, không nhất thiết bao hàm giá trị kỳ vọng về dịch vụ là một thành phần cần thiết nhằm xác định chất lượng dịch vụ. Nói cách khác là chất lượng dịch vụ là mức đánh giá cảm nhận của khách hàng (Brady, 
Cronin, \& Brand, 2002; Lee, Lee, \& Yoo, 2000). Mô hình SERVPERF cũng có 5 khía cạnh cơ bản như mô hình chất lượng dịch vụ SERVQUAL là: yếu tố hữu hình (vật chất), sự tin cậy, khả năng đáp ứng, sự đảm bảo và đồng cảm; và 22 các thuộc tính (biến quan sát) trong từng khía cạnh được đo lường theo thang đo Likert (Cronin \& Taylor, 1992; Etemad-Sajadi \& Rizzuto, 2013; Jain \& Gupta, 2004).

Nhiều nghiên cứu liên quan gần đây về chất lượng dịch vụ hành chính công và sự hài lòng của khách hàng sử dụng các khía cạnh và bổ sung biến quan sát chất lượng dịch vụ của thang đo SERVQUAL nhưng chỉ đo lường phần đánh giá cảm nhận SERVPERF (Agus, Barker, \& Kandampully, 2007; Hadiyati, 2014; Mokhlis \& Aleesa, 2011; Ngo, La, Ho, \& Nguyen, 2019; M. P. Nguyen, Hoang, \& Nguyen, 2016; Pham \& Le, 2018). Các kết quả nghiên cứu cũng khẳng định tính đơn giản và hợp lý của mô hình SERVPERF.

\section{Phương pháp thực hiện nghiên cứu}

\subsection{Mô hình nghiên cúu}

Dựa trên cở sở lý thuyết và nghiên cứu ứng dụng trong lĩnh vực hành chính công, mô hình SERVPERF được áp dụng trong nghiên cứu này. Các yếu tố cấu thành chất lượng dịch vụ dựa theo mô hình SERVQUAL của Parasuraman và cộng sự (1988), nhưng chỉ khảo sát phần cảm nhận theo mô hình SERVPERF (Cronin \& Taylor, 1992), không khảo sát kỳ vọng của khách hàng.

Chất lượng dịch vụ trong nghiên cứu gồm 26 biến quan sát được trích lọc từ các nghiên cứu liên quan đến chất lượng dịch vụ hành chính công đã trình bày trong phần cơ sở lý thuyết và thực tiễn, trong đó có 9 biến từ thang đo của Bộ Nội vụ. Thang đo hài lòng bao gồm 3 biến quan sát đo lường hài lòng kết quả dịch vụ trích từ thang đo của Bộ Nội vụ̂ và bổ sung 1 biến đo lường sự hài lòng khi so sánh với dịch vụ được cung cấp từ các tổ chức hành chính khác. Các biến được đo lường theo thang đo Likert 5 mức độ, với $5=$ hoàn toàn hài lòng/đồng ý; 4 = hài lòng/đồng ý; $3=$ phân vân/trung dung; 2 = không hài lòng/đồng ý; và $1=$ hoàn toàn không hài lòng/đồng ý. Điểm được đánh giá càng cao thể hiện chất lượng dịch vụ hay mức hài lòng càng cao. Bảng khảo sát, bên cạnh phần thứ nhất là các yếu tố chất lượng dịch vụ và sự hài lòng, phần thứ 2 là các thông tin về đặc điểm của cá nhân: tuổi, giới tính, trình độ học vấn, nghề nghiệp, loại hình dịch vụ.

\subsection{Phương pháp thu thập và phân tích số liệu}

Bảng khảo sát hoàn chỉnh được sử dụng để thu thập thông tin từ người dân vào thời điểm nhận kết quả dịch vụ hành chính, tại Bộ phận tiếp nhận và trả kết quả, thuộc UBND huyện Châu Phú, tỉnh An Giang, vào tháng 9 năm $2020^{2}$. Tổng số phiếu khảo sát thu thập hoàn chỉnh được sử dụng để phân tích là $n=172$ (tỷ lệ $95 \%$ ).

Giá trị hệ số Cronbach's Alpha được sử dụng để đo lường sự nhất quán bên trong của một cấu trúc (yếu tố) có nhiều biến quan sát, và độ tin cậy của yếu tố được chấp nhận cao khi hệ số này đạt 0,70 (Cronbach, 1951). Phân tích khám phá yếu tố (EFA) được thực hiện để xác định các khía cạnh (yếu tố) cảm nhận về chất lượng dịch vụ. Mô hình hồi quy bội, ước lượng theo phương pháp bình phương bé nhất (OLS) được áp dụng để xem xét khía cạnh nào của chất lượng dịch vụ ảnh hưởng mạnh nhất đến sự hài lòng chung và từng mục của sự hài lòng. Kỹ thuật thống kê mô tả cũng được sử dụng bao gồm số trung bình, độ lệch chuẩn, bảng phân tích hai chiều, phân tích ANOVA một chiều theo giá trị khác biệt nhỏ nhất có nghĩa (LSD) về mức độ hài lòng theo đặc điểm cá nhân.

\footnotetext{
${ }^{1}$ Quyết định Phê duyệt Đề án Đo lường sự hài lòng của người dân, tổ chức đối với sự phục vụ của cơ quan hành chính nhà nước giai đoạn 2017 - 2020. Số 2640/QĐ-BNV, ngày 10/10/2017.

${ }^{2}$ Cảm ơn sự trợ giúp tổ chức, thu thập số liệu của Ông Nguyễn Nghi Em, Ban tổ chức Huyện ủy Huyện Châu Phú, tỉnh An Giang.
} 


\section{Kết quả nghiên cứu}

\subsection{Các yếu tố cấu thành chất lựng dịch vụ}

Phân tích EFA nhằm khám phá ra những cấu trúc bên trong của dữ liệu chất lượng dịch vụ (Parasuraman et al., 1988; Fabrigar, Wegener, MacCallum, \& Strahan, 1999). Một trong những tiêu chuẩn quan trọng để phân tích EFA là mức độ tương quan giữa các biến. Kết quả phân tích giá trị chỉ số thống kê Kaiser-Meyer-Olkin (KMO) và kiểm định Bartlett đo lường mức độ phù hợp của các biến đại diện cho một yếu tố hay cấu trúc và giữa các biến có tương quan với nhau. Kết quả chỉ số $\mathrm{KMO}=090$, khá cao; đồng thời, hệ số tương quan giữa các biến lớn hơn 0,3 ; kiểm định Bartlett về mức độ tương quan của các biến có giá trị $\chi^{2}(\mathrm{df}: 276)=1875,02$, có ý nghĩa thống kê ở mức $1 \%$. Điều này, khẳng định các biến quan sát là phù hợp, có thể đại diện cho cấu trúc chất lượng dịch vụ, và có thể tiến hành phân tích EFA (Hair, Anderson, Tatham, \& Black, 1998).

Các thành phần (yếu tố) được trích phải đạt tiêu chuẩn giá trị Eigen lớn hơn 1 để kiểm soát số yếu tố được trích, và các biến quan sát được tải lên các yếu tố có giá trị từ 0,50 trở lên sẽ được giữ lại. Kết quả phân tích EFA, với phương pháp trích PCA (principle component analysis) và cách xoay Varimax, đã loại 2 biến quan sát do không đạt tiêu chuẩn hệ số tải lớn hơn 0,5 ; và nhóm 24 biến còn lại thành 5 yếu tố cấu thành chất lượng dịch vụ với giá trị Eigen lần lượt là: 4,45; 3,24; 2,$98 ; 2,54$; và 1,70 . Tổng 5 yếu tố chất lượng dịch vụ đại diện được $62,06 \%$ phương sai từ số liệu ban đầu, thỏa mãn yêu cầu về tiêu chuẩn \% phương sai trích từ phân tích EFA. Hệ số Cronbach's Alpha của các yếu tố đạt giá trị từ 0,69 đến 0,90 (Bảng 1 ), cho thấy mức độ tin cậy cao về sự nhất quán bên trong của các biến quan sát trong mỗi yếu tố đại diện được cho thuộc tính của một cấu trúc (Hair et al., 1998). Tóm lại, kết quả từ phân tích EFA cho thấy giá trị hội tụ và giá trị phân biệt của các yếu tố được trích đạt yêu cầu, và được sử dụng trong những phân tích tiếp theo.

Các biến quan sát được xếp vào trong 5 yếu tố giống như mô hình lý thuyết SERVQUAL với tên gọi và khái niệm cụ thể là: a) Cơ sở Vật chất (6 biến) liên quan đến các phương tiện hữu hình, những tiện ích, trang thiết bị, trang phục nhân viên tại nơi người dân tiếp cận để yêu cầu thực hiện dịch vụ; b) Sự tin cậy ( 5 biến) là niềm tin về khả năng cung cấp dịch vụ nhất quán, chính xác đúng quy định về thời gian, lệ phí; c) Năng lực phục vụ (4 biến) tập trung vào khía cạnh kiến thức chuyên môn, kỹ năng giao tiếp và giải quyết của công chức; $d)$ Thái độ phục vụ ( 5 biến) là các thuộc tính của công chức phục vụ về thái độ phục vụ, tính khách quan, nhanh nhẹn trong công việc, tạo dựng niềm tin trong lòng người dân; và e) Sự Đồng cảm (4 biến) là các đánh giá về tâm lý của người dân về sự tôn trọng, cách cư xử, hiểu biết được yêu cầu dịch vụ trong những hoàn cảnh cụ thể của công chức thực hiện dịch vụ.

\section{2. Đánh giá cảm nhận về chất lự̛̣ng dịch vụ}

Điểm trung bình đánh giá cảm nhận của người dân được khảo sát về các yếu tố thành phần chất lượng dịch vụ tại Bộ phận tiếp nhận và trả kết quả thuộc UBND huyện Châu Phú, tỉnh An Giang của trình bày trong Bảng 1 , có giá trị từ 3,31 đến 4,18 , và độ lệch chuẩn từ 0,69 đến 0,84 . Với giá trị trung bình này cho thấy có 4 yếu tố chất lượng dịch vụ nằm trong khoảng hài lòng (đồng ý) đạt mức khá $(3,4-4,2)$. Trong đó yếu tố Năng lực công chức thực hiện nhiệm vụ được đánh giá cao nhất (điểm $4,18 \pm 0,69$ ), với cận trên của khoảng tin cậy $95 \%$ là 4,87 đạt mức rất hài lòng (rất tốt/ rất đồng ý) theo đánh giá của người dân. Điểm số hài lòng tiếp theo là Thái độ phục vụ $(3,70 \pm 0,74)$, cơ sở Vật chất $(3,69 \pm 0,81)$, Tin cậy về dịch vụ được cung cấp $(3,60 \pm 0,81)$. Yếu tố Đồng cảm mang đậm cảm nhận về tâm lý chưa được đánh giá cao, mức hài lòng chỉ đạt mức trung bình $(3,31 \pm 0,84)$. Độ lệch chuẩn của số trung bình càng nhỏ thể hiện mức độ tin cậy càng cao của số trung bình. Độ lệch chuẩn của yếu tố Đồng cảm là cao nhất cho thấy mỗi người có cách nhìn và đánh giá khá khác nhau về cách người khác (công chức thực hiện nhiệm vụ) hiểu 
được cảm xúc, hoàn cảnh riêng của cá nhân.

Xem xét đánh giá cảm nhận của người dân trên khía cạnh tổng tỷ lệ ý kiến đồng ý (hoặc hài lòng) và hoàn toàn đồng ý của các yếu tố cấu thành dịch vụ, kết quả Bảng 1 cũng cho thấy tỷ lệ này cao nhất $(79,65 \%)$ ở yếu tố Năng lực. Trong yếu tố Năng lực có $81,91 \%$ ý kiến đánh giá cao về $k h a ̉$ năng giao tiếp, và kiến thức để trả lời các câu hỏi của Công chức tiếp nhận hồ sơ. Tiếp đến là yếu tố Thái độ phục vụ $(63,2 \%)$, Cơ sở vật chất $(59,88 \%)$, Sự tin cậy $(55,58 \%)$. Yếu tố Sự Đồng cảm có tỷ lệ dưới 50\% nhất (46,37\%); trong đó mức độ tận tình chu đáo và trả lời/giải thích đầy đủy kiến của người dân có tỷ tệ đồng ý trở lên là thấp nhất $(39,53 \%)$ trong tất cả các biến quan sát.

\section{Bảng 1}

Đánh giá cảm nhận về chất lượng dịch vụ

\begin{tabular}{|c|c|c|c|}
\hline Yếu tố, thuộc tính, hệ số tin cậy & $\begin{array}{l}\text { Trung } \\
\text { bình }\end{array}$ & STD & $\begin{array}{c}\text { Đồng ý } \\
\% *\end{array}$ \\
\hline Cronbach's Alpha = 0,762 & 3,60 & $\mathbf{0 , 8 1}$ & $\mathbf{5 5 , 5 8}$ \\
\hline Các quy trình, thủ tục hành chính được niêm yết công khai đầy đủ. & 3.59 & 1,22 & 57,56 \\
\hline Các quy trình, thủ tục được niêm yết công khai chính xác. & 3,67 & 1,09 & 56,98 \\
\hline Thành phần hồ sơ phải nộp là đúng quy định. & 3,77 & 1,15 & 60,47 \\
\hline Phí/lệ phí phải nộp là đúng quy định. & 3,42 & 1,08 & 49,42 \\
\hline Thời hạn giải quyết hồ sơ là đúng quy định (theo giấy hẹn trả). & 3,51 & 1,14 & 53,49 \\
\hline Co’ sở vật chất $\quad$ Cronbach's Alpha $=0,882$ & 3,69 & $\mathbf{0 , 8 1}$ & 59,88 \\
\hline Nơi tiếp nhận và trả hồ sơ rộng rãi, thoáng mát. & 3,52 & 1,13 & 54,07 \\
\hline Nơi tiếp nhận và trả hồ sơ có đầy đủ chổ ngồi cho người dân. & 3,65 & 1,12 & 59,30 \\
\hline Nơi tiếp nhận và trả hồ sơ có cách bố trí, sắp xếp hợp lý. & 3,51 & 1,05 & 48,84 \\
\hline $\begin{array}{l}\text { Trang thiết bị phục vụ người dân tại nơi tiếp nhận và trả hồ sơ turơng } \\
\text { đối hiện đại. }\end{array}$ & 3,61 & 1,04 & 59,88 \\
\hline $\begin{array}{l}\text { Trang thiết bị phục vụ người dân tại nơi tiếp nhận và trả hồ sơ dễ sủ } \\
\text { dụng (máy lấy số tự động, tiếp cận wifi,...) }\end{array}$ & 4,02 & 0,86 & 75,00 \\
\hline Trang phục của công chức gọn gàng phù hợp tại nơi làm việc. & 3,81 & 0,87 & 62,21 \\
\hline Cronbach's Alpha $=0,902$ & 4,18 & 0,69 & 79,65 \\
\hline Công chức làm việc nhận/ trả hồ sơ có khả năng giao tiếp tốt. & 4,24 & 0,79 & 81,98 \\
\hline Công chức làm việc thành thạo chuyên môn và nghiệp vụ. & 4,18 & 0,76 & 80,81 \\
\hline Công chức làm việc có kiến thức trả lời các câu hỏi của ông (bà). & 4,21 & 0,79 & 81,98 \\
\hline $\begin{array}{l}\text { Hành vi của Công chức làm việc ngày càng tạo sự tin tưởng đối với } \\
\text { ông (bà). }\end{array}$ & 4,08 & 0,79 & 73,84 \\
\hline Thái độ phục vụ $\quad$ Cronbach’s Alpha = 0,782 & 3,70 & 0,74 & 63,02 \\
\hline Công chức tiếp nhận và giải quyết hồ sơ có thái độ lịch sự. & 3,72 & 0,97 & 64,53 \\
\hline Công chức chú ý lắng nghe ý kiến khi giải quyết công việc. & 3,58 & 1,07 & 56,40 \\
\hline Công chức không có thái độ gây khó dễ (làm phiền hà). & 3,78 & 0,97 & 66,86 \\
\hline
\end{tabular}




\begin{tabular}{|l|c|c|c|}
\hline \multicolumn{1}{|c|}{ Yếu tố, thuộc tính, hệ số tin cậy } & $\begin{array}{c}\text { Trung } \\
\text { bình }\end{array}$ & STD & $\begin{array}{c}\text { Đồng ý } \\
\mathbf{\%}\end{array}$ \\
\hline Công chức tuân thủ đúng quy định khi giải quyết công việc. & 3,72 & 1,00 & 62,21 \\
\hline Công chức hướng dẫn cách thức hoàn thành hồ sơ dễ hiểu. & 3,72 & 1,03 & 65,12 \\
\hline Sự đồng cảm Cronbach's Alpha = 0,685 & $\mathbf{3 , 3 1}$ & $\mathbf{0 , 8 4}$ & $\mathbf{4 6 , 3 7}$ \\
\hline $\begin{array}{l}\text { Công chức làm việc thể hiện sự tôn trọng cần thiết với cá nhân ông } \\
\text { (bà) tại nơi công cộng. }\end{array}$ & 3,80 & 1,07 & 63,37 \\
\hline Công chức làm việc tận tình chu đáo. & 3,11 & 1,23 & 39,53 \\
\hline Công chức làm việc hiểu rõ nhưng yêu cầu cu thể của ông (bà). & 3,23 & 1,17 & 43,02 \\
\hline Công chức làm việc trả lời đầy đủ các ý kiến của ông (bà). & 3,10 & 1,23 & 39,53 \\
\hline
\end{tabular}

Ghi chú: *: tổng tỷ lệ số ý kiến đánh giá đồng ý (mức 4) và hoàn toàn đồng ý (mức 5). STD: Độ lệch chuẩn Nguồn: Kết quả phân tích dữ liệu của nhóm nghiên cứu

\subsection{Sụ̂ hài lòng với kết quả dịch vụ}

Kết quả khảo sát cho thấy người dân hài lòng với kết quả dịch vụ khá cao. Có đến 72,5\% người dân cho biết hài lòng với kết quả chung về dịch vụ bao gồm 4 biến quan sát hài lòng, với điểm trung bình của yếu tố dịch vụ là $3,93 \pm 0,53$, và $2,5 \%$ người dân không hài lòng với kết quả dịch vụ (4 người/172 người).

Hình 1 trình bày chi tiết sự hài lòng kết quả theo từng mục. Hài lòng với Kết quả dịch vu là đúng theo quy định được 71,5\% ý kiến đồng ý và rất đồng ý, điểm trung bình là 3,94 $\pm 0,74$. Nói cách khác là người dân hài lòng vì kết quả giải quyết dịch vụ đúng theo quy định. Khía cạnh thông tin đầy đủ của kết quả $68 \%$, điểm trung bình là 3,88 $\pm 0,78$. 77,3\% hài lòng với thông tin chính xác của kết quả, điểm trung bình là $3,95 \pm 0,74$. Sau cùng là $73,2 \%$ ý kiến cho biết họ hài lòng với dịch vụ được cung cấp tại Bộ phận tiếp nhận và trả kết quả thuộc UBND huyện Châu Phú khi so sánh với dịch vụ được cung cấp tại các cơ quan hành chính khác, điểm trung bình 3,95 \pm 0,77 .

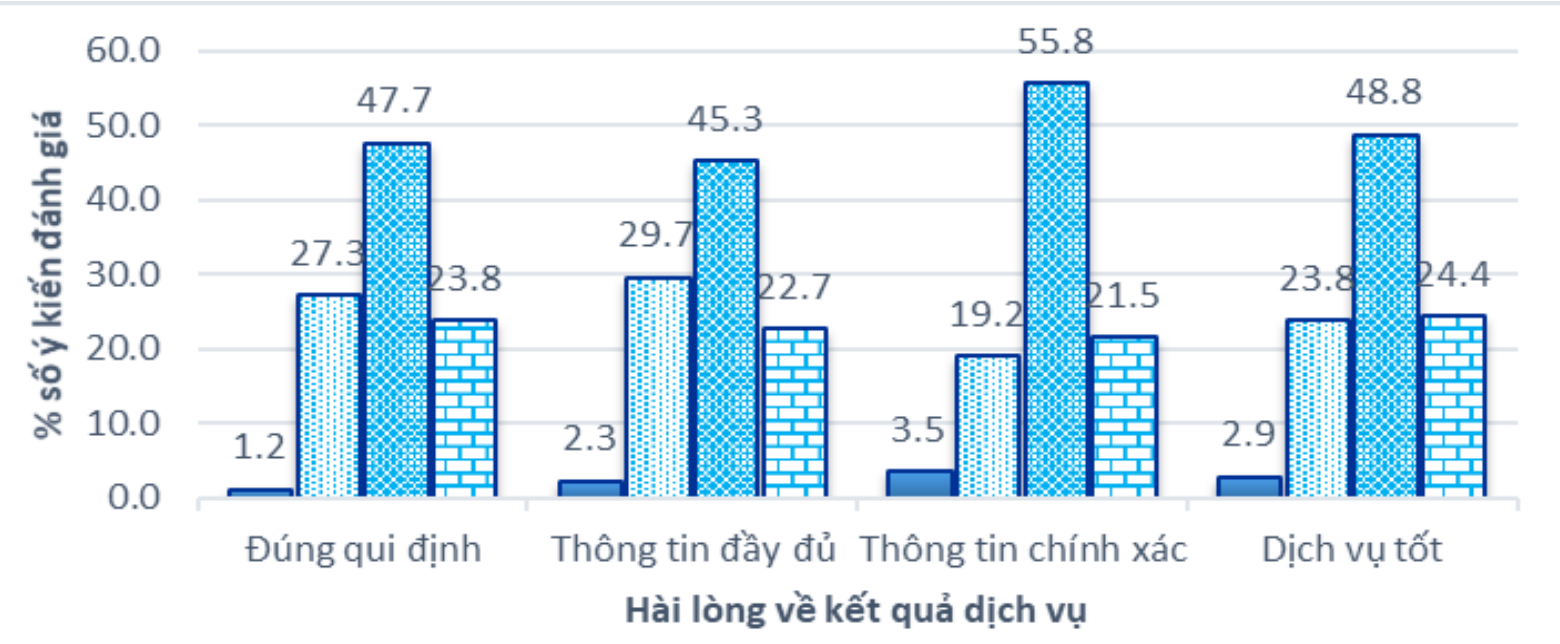

Không đồng ý 国Phân vân 圆Đồng ý 巴Rất đồng ý

Hình 1. Sự hài lòng về kết quả dịch vụ 
Một số đặc điểm khác ngoài các yếu tố khác cũng có thể ảnh hưởng đến sự hài lòng của người dân (Dimitriades \& Maroudas, 2007). Kết quả phân tích theo giới tính cho thấy điểm số hài lòng của nam $(3.88 \pm 0,49)$ và nữ $(3.98 \pm 0,56)$ cách biệt nhau quá nhỏ $(0,1$ điểm) và giá trị kiểm định $\mathrm{t}=1,233$ không có nghĩa về mặt thống kê. Nói cách khác là nam và nữ có mức độ hài lòng như nhau. Tương tự như vậy, mặc dù có sự chênh lệch về số trung bình, sự hài lòng phân chia theo trình độ học vấn theo kết quả phân tích ANOVA một chiều cho thấy không có sự khác biệt có ý nghĩa, kiểm định thống kê $\mathrm{F}(6,171)=0,844$ ns. Sự hài lòng của người dân giữa các nghề nghiệp khác nhau được khẳng định là tương tự như nhau, kiểm định thống kê $\mathrm{F}(4,171)=1,001$ ns. Tuy nhiên, giữa các loại hình dịch vụ khác nhau có sự hài lòng khác biệt nhau. Kết quả phân tích $\mathrm{F}$ $(7,171)=1824^{*}$ và kiểm định $\mathrm{t}$ theo từng cặp cho thấy thủ tục đất đai, tư pháp-hộ tịch, và kinh doanh có sự khác biệt về hài lòng ở mức ý nghĩa thống kê 5\% so với các loại dịch vụ khác.

\subsection{Mối quan hệ giữa các yếu tố chất lự̣ng dịch vụ và sụ hài lòng}

Kết qủa 5 phân tích hồi quy được thực hiện để xem xét mối quan hệ và ảnh hưởng của các yếu tố chất lượng dịch vụ đến từng mục hài lòng và hài lòng chung được trình bày trong Bảng 2 .

Kết quả kiểm định sự phù hợp của mô hình mối quan hệ giữa mức độ hài lòng chung và các yếu tố chất lượng dịch vụ (mô hình 5 ) có giá trị $\mathrm{F}(5,171)=19,960$ đạt mức ý nghĩa thống kê $1 \%$, và $\mathrm{R}^{2}=0,63$ khẳng định các yếu tố chất lượng dịch vụ có ảnh hưởng và giải thích được $63 \%$ sự hài lòng của người dân. Tỷ lệ $37 \%$ chưa giải thích được của mô hình là do còn có những ảnh hưởng khác như các đặc điểm nhân chủng học (Dimitriades \& Maroudas, 2007). Đồng thời mô hình cũng thỏa mãn yêu cầu ước lượng OLS là hiện tượng đa cộng tuyến không phải là vấn đề (hệ số $\mathrm{VIF}<10$ ), và phần dư có phân phối chuẩn với giá trị trung bình bằng 0 và độ lệch chuẩn xấp xỉ bằng 1 .

\section{Bảng 2}

Ảnh hưởng của các yếu tố chất lượng dịch vụ đến sự hài lòng

\begin{tabular}{|c|c|c|c|c|c|c|}
\hline Giá trị & (Constant) & Vật chất & Năng lụ̣c & Thái độ & Tin cậy & Đồng cảm \\
\hline & \multicolumn{3}{|c|}{ 1. Kết quả đúng quy định } & $\mathrm{R}^{2}=0,52$ & \multicolumn{2}{|c|}{$\mathrm{F}(5,171)=12,510^{* * *}$} \\
\hline Hệ số $\beta$ & $0,027 \mathrm{~ns}$ & $0,199 * * *$ & $0,395 * * *$ & $0,160^{* *}$ & $0,165^{* * *}$ & $0,105^{*}$ \\
\hline Sai số & 0,505 & 0,063 & 0,072 & 0,072 & 0,061 & 0,061 \\
\hline \multirow[t]{2}{*}{ VIF } & - & 1,046 & 1,018 & 1,141 & 1,018 & 1,085 \\
\hline & \multicolumn{3}{|c|}{ 2. Kết quả có đầy đủ thông tin } & $\mathrm{R}^{2}=0,42$ & \multicolumn{2}{|c|}{$\mathrm{F}(5,171)=7,069^{* * *}$} \\
\hline Hệ số $\beta$ & $0,622 \mathrm{~ns}$ & $0,130 *$ & $0,328 * * *$ & $0,159 * *$ & $0,118^{*}$ & $0,120^{*}$ \\
\hline Sai số & 0,561 & 0,070 & 0,080 & 0,080 & 0,068 & 0,068 \\
\hline \multirow[t]{2}{*}{ VIF } & - & 1,046 & 1,018 & 1,141 & 1,018 & 1,085 \\
\hline & \multicolumn{3}{|c|}{ 3. Thông tin kết quả chính xác } & $\mathrm{R}^{2}=0,44$ & \multicolumn{2}{|c|}{$\mathrm{F}(5,171)=7,797 * * *$} \\
\hline Hệ số $\beta$ & $0,774 \mathrm{~ns}$ & $0,174 * * *$ & $0,202 * * *$ & $0,145^{* *}$ & $0,186^{* * *}$ & $0,147 * *$ \\
\hline Sai số & 0,528 & 0,066 & 0,076 & 0,075 & 0,064 & 0,064 \\
\hline \multirow[t]{2}{*}{ VIF } & - & 1,046 & 1,018 & 1,141 & 1,018 & 1,085 \\
\hline & \multicolumn{3}{|c|}{ 4. Hài lòng dịch vụ tại nơi cung cấp } & $\mathrm{R}^{2}=0,37$ & \multicolumn{2}{|c|}{$\mathrm{F}(5,171)=5,216^{* * *}$} \\
\hline Hệ số $\beta$ & $1,188^{*}$ & $0,129^{*}$ & $0,169 * *$ & $0,161 * *$ & $0,133^{*}$ & $0,152 * *$ \\
\hline
\end{tabular}




\begin{tabular}{|l|c|c|c|c|c|c|}
\hline Giá trị & (Constant) & Vật chất & Năng lực & Thái độ & Tin cậy & Đồng cảm \\
\hline Sai số & 0,571 & 0,071 & 0,082 & 0,081 & 0,069 & 0,069 \\
\hline VIF & - & 1,046 & 1,018 & 1,141 & 1,018 & 1,085 \\
\hline & 5. Mức độ hài lòng chung về dịch vụ & \multicolumn{2}{|c|}{$\mathrm{R}^{2}=0,63$} & $\mathrm{~F}(5,171)=19,960 * * *$ \\
\hline Hệ số $\beta$ & $0,653 * *$ & $0,158 * * *$ & $0,274 * * *$ & $0,156 * * *$ & $0,151 * * *$ & $0,131 * * *$ \\
\hline Sai số & 0,332 & 0,041 & 0,048 & 0,047 & 0,040 & 0,040 \\
\hline VIF & - & 1,046 & 1,018 & 1,141 & 1,018 & 1,085 \\
\hline
\end{tabular}

Ghi chú: *,***** chỉ mức ý nghĩa thống kê theo thứ tự $10 \%, 5 \%$, và $1 \%$.

Nguồn: Kết quả phân tích dữ liệu của nhóm nghiên cứu

Tất cả các yếu tố đều có tác động làm tăng sự hài lòng và hệ số ước lượng $\beta$ s có ý nghĩa thống kê từ $10 \%$ trở lên. Yếu tố Năng lực có ảnh hưởng mạnh nhất đến sự hài lòng, với giá trị ước lượng $\left(\beta=0.274^{* * *}\right)$, điều này rất phù hợp với phân tích sự hài lòng của người dân với yếu tố Năng được trình bày ở phần trên. Yếu tố có ảnh hưởng mạnh tiếp theo là cơ sở Vật chất $((\beta=$ $0.158)$, Thái độ phục vụ $(\beta=0.156$, và Tin cậy $(\beta=0.151)$ ). Yếu tố Đồng cảm ảnh hưởng thấp nhất $(\beta=0.131)$ và cũng phù hợp với kết quả phân tích thống kê mô tả về hài lòng của người dân đối với sự đồng cảm của công chức thực hiện nhiệm vụ.

Phân tích riêng về ảnh hưởng của các yếu tố chất lượng dịch vụ đến sự hài lòng kết quả đúng theo quy định (mô hình 1), kết quả có đầy đủ thông tin (mô hình 2), kết quả có thông tin chính xác (mô hình 3), và hài lòng với dịch vụ tại Bộ phận tiếp nhận và trả kết quả (mô hình 4) cũng cho thấy tất cả 4 mô hình đều đạt mức độ phù hợp (kiểm định $\mathrm{F}$ có ý nghĩa ở mức $1 \%$ ), không có hiện tượng đa cộng tuyến, phần dư có phân phối chuẩn. Mặc dù, khả năng giải thích của các yếu tố chất lượng dịch vụ $-\mathrm{R}^{2}$ đến sự hài lòng theo từng thuộc tính của kết quả không cao (từ $37 \%$ đến $52 \%$ ), nhưng tất cả các yếu tố đều có ảnh hưởng làm gia tăng sự hài lòng và có ý nghĩa thống kê từ mức $10 \%$ đến $1 \%$. Trong cả 4 mô hình, thì yếu tố Năng lực đều có ảnh hưởng mạnh nhất đến sự hài lòng, và yếu nhất là yếu tố Đồng cảm.

\section{Kết luận và hàm ý quản trị}

Nội dung chính của nghiên cứu là xác định các yếu tố cấu thành chất lượng dịch vụ hành chính công và ảnh hưởng của các yếu tố này đến sự hài lòng kết quả dịch vụ được thực hiện tại Bộ phận giao nhận và trả kết quả, thuộc UBND huyện Châu Phú, tỉnh An Giang. Kết quả đã khẳng định chất lượng dịch vụ hành chính được cung cấp tại huyện đạt mức độ hài lòng của người dân. Năm yếu tố cấu thành chất lượng dịch vụ được xác định thì hầu như tương tự với các cấu trúc đề xuất của Parasuraman và cộng sự (1988). Yếu tố Đồng Cảm và Thái độ không được đề cập trong thang đo của Bộ Nội Vụ là bộ phận cấu thành của chất lượng dịch vụ trong nghiên cứu này. Kết quả về khả năng giải thích của mô hình cho thấy còn nhiều yếu tố khác ảnh hưởng đến đánh giá cảm nhận về chất lượng, nhưng các cấu trúc cơ bản trong thang đo SERVQUAL (giải thích $63 \%$ sự hài lòng) là phù hợp và để sử dụng trong đánh giá chất lượng dịch vụ hành chính tại địa phương cấp huyện.

Nghiên cứu cũng đã nỗ lực để xác định những khía cạnh nào có ảnh hưởng quan trọng đến sự hài lòng của người dân về dịch vụ được cung cấp. Kết quả cho thấy các yếu tố chất lượng dịch vụ đều có ảnh hưởng quan trọng đến sự hài lòng, tương tự như những nghiên cứu khác (Cronin \& Taylor, 1992; Rodríguez, Burguete, Vaughan, \& Edwards, 2009). Năm yếu tố chất lượng dịch vụ giải thích được $63 \%$ sự hài lòng của người dân. Năng lực của công chức thực hiện nhiệm vụ có 
tác động gia tăng mạnh nhất sự hài lòng, tiếp đến là cơ sở Vật chất, Thái độ phục vụ, sự Tin cậy, và sự Đồng cảm.

Kết quả nghiên cứu chứa đựng nhiều hàm ý quản trị quan trọng cho UBND huyện nhằm có những giải pháp cải thiện nhằm cung cấp các dịch vụ có chất lượng hơn và nâng cao sự hài lòng. Với tầm quan trọng hàng đầu của yếu tố Năng lực phục vụ đến sự hài lòng, cần có những hoạt động tiếp tục bồi dưỡng kiến thức, kỹ năng chuyên môn, giải quyết vấn đề, ngày càng tạo được niềm tin trong lòng người dân về năng lực cán bộ. Duy trì số lượng cán bộ phù hợp với lượng cầu dịch vụ để bảo đảm cung ứng dịch vụ nhanh, và trả kết quả đúng hẹn. Đây có thể xem là một biện pháp mang tính chiến lược trong các biện pháp cải thiện, phát huy điểm mạnh hiện nay của công chức đang thực thi nhiệm vụ.

Yếu tố hữu hình gồm những trang thiết bị phục vụ, dễ dàng và thuận tiện để tiếp cận dịch vụ tại nơi tiếp nhận và trả hồ sơ có tầm quan trọng thứ 2 đến sự hài lòng. Cán bộ công chức cần có biện pháp bảo dưỡng thiết bị, tăng cường thêm các tiện ích, điều kiện thoải mái cho người dân. Trong đó, cần gìn giữ hình ảnh đẹp trong người dân về trang phục hiện nay tại nơi làm việc, và nghiên cứu cải thiện cách bố trí sơ đồ làm việc tại nơi tiếp nhận và trả hồ sơ hợp lý hơn. Tăng cường trang bị những tiện ích phục vụ cho công việc của công chức, vì những trang bị này ảnh hưởng đến cảm nhận của người dân về rủi ro, kinh nghiệm, hiệu quả cung cấp dịch vụ của tổ chức (Ramseook-Munhurrun et al., 2010).

Thái độ phục vụ cũng là yếu tố liên quan đến con người, khác với Năng lực của công chức, ảnh hưởng mạnh thứ 3 đến sự hài lòng. Cần nhân rộng và huấn luyện công chức về thái độ cư xử lịch sự, biết lắng nghe; giảm thiểu những thái độ gây khó dễ, phiền hà trong cung cấp dịch vụ.

Để tiếp tục nâng cao tính minh bạch và hiệu quả trong cung cấp các dịch vụ tại cơ quan hành chính cấp huyện, tiếp tục duy trì việc niêm yết công khai các quy trình, thủ tục, thành phần hồ sơ cần thiết cho các loại dịch vụ tại nơi làm việc và cổng thông tin điện tử cấp huyện. Đặc biệt lưu ý đến việc thu lệ phí phải đúng quy định, và bảo đảm trả kết quả đúng thời điểm đã ghi trên giấy hẹn trả vì hai điểm này chưa nhận được sự đồng ý cao từ phía người dân.

Sau cùng là cần tổ chức bồi dưỡng kiến thức tâm lý khách hàng cho công chức thực thi nhiệm vụ, vì yếu tố này chưa được người dân đánh giá cao. Những đặc điểm nhân chủng học của con người khác nhau về trình độ học vấn, tuổi tác, giới tính; yêu cầu dịch vụ khác nhau, môi trường sống và quan hệ xã hội đã hình thành nhận thức, tâm lý của mỗi người. Mặc dù, cung cấp dịch vụ công được yêu cầu là minh bạch, không thiên vị, và nhất quán, điều đó không có nghĩa là không nhất thiết phải lắng nghe chi tiết, nhiệt tình, tôn trọng và hiểu biết tâm lý người dân để thấu hiểu được những hoàn cảnh cụ thể, cá biệt trong một số trường hợp để có cách giải quyết hợp lý đúng quy định và cũng rất hợp tình.

Kết quả nghiên cứu bước đầu này tại địa phương có thể xem là một kết quả làm nền tảng để so sánh loại dịch vụ này trong những khảo sát đánh giá về sau. Các đánh giá chất lượng dịch vụ hàng năm giúp chính quyền địa phương hiểu được tác dụng của những biện pháp cải thiện chất lượng cụ thể được đề ra cho từng yếu tố; mức độ hài lòng được nâng lên thế nào; và nắm bắt được xu hướng thay đổi nhu cầu dịch vụ và mong muốn của người dân.

\section{Tài liệu tham khảo}

Agus, A., Barker, S., \& Kandampully, J. (2007). An exploratory study of service quality in the Malaysian public service sector. International Journal of Quality \& Reliability Management, 24, 177-190. doi:10.1108/02656710710722284 
Baffour-Awuah, E. (2018). A primary examination of SERVPERF dimensions and customer satisfaction relationship in the automotive electrical maintenance service industry. IJISET International Journal of Innovative Science, Engineering \& Technology, 5(3), 104-116.

Brady, M. K., Cronin, J. J., \& Brand, R. R. (2002). Performance-only measurement of service quality: A replication and extension. Journal of Business Research, 55(1), 17-31.

Cronbach, L. J. (1951). Coefficient alpha and the internal structure of tests. Psychometrika, 16, 297-334. doi:10.1007/BF02310555.

Cronin, J. J., \& Taylor, S. A. (1992). Measuring service quality: A re-examination and extension. Journal of Marketing, 56(3), 55-68.

Dimitriades, Z. S., \& Maroudas, T. S. (2007). Demographic predictors of service satisfaction in Greek public organizations. Measuring Business Excellence, 11(2), 32-43.

Dutta, K., \& Dutta, A. (2009). Customer expectations and perceptions across the Indian banking industry and resultant financial implications. Journal of Services Research, 9(1), 31-49.

Etemad-Sajadi, R., \& Rizzuto, D. (2013). The antecedents of customer satisfaction and loyalty in fast food industry: A cross-national comparison between Chinese and Swiss consumers. International Journal of Quality and Reliability Management, 30(7), 731-749.

Fabrigar, L. R., Wegener, D. T., MacCallum, R. C., \& Strahan, E. J. (1999). Evaluating the use of exploratory factor analysis in psychological research. Psychological Methods, 4(3), 272-299.

Hadiyati, E. (2014). Service quality and performance of public sector: Study on immigration office in Indonesia. International Journal of Marketing Studies, 6(6), 104-117.

Hair, J. F., Anderson, R. E., Tatham, R. R., \& Black, W. E. (1998). Multivariate data analysis. Upper Saddle River, NJ: Prentice-Hall International Inc.

Jain, S. K., \& Gupta, G. (2004). Measuring service quality, SERVQUAL vs SERVPERF scales. Vikalpa, 29(2), 25-37.

Lee, H., Lee, Y., \& Yoo, D. (2000). The determinants of perceived service quality and its relationship with satisfaction. Journal of Services Marketing, 14(3), 217-231.

Mokhlis, S., \& Aleesa, Y. (2011). Municipal service quality and citizen satisfaction in Southern Thailand. Journal of Public Administration and Governance, 1(1), 122-137.

Ngo, L. T. T., La, M. V. H., Ho, K., \& Nguyen, N. H. (2019). Sự hài lòng của người dân đối với chất lượng dịch vụ công khi thực hiện các quyền về đất đai tại thành phố Cao Lãnh, tỉnh Đồng Tháp [People's satisfaction with public service quality when exercising land rights in Cao Lanh City, Dong Thap province]. Tạp chí Khoa học Đại học Huế: Nông nghiệp và Phát triển nông thôn, 128(3C), 87-98. doi:10.26459/hueuni-jard.v128i3C.5219

Nguyen, M. P., Hoang, H. V., \& Nguyen, D. V. (2016). Factors influencing citizens' satisfaction with public administrative services at the grassroots level case study of Tay Ho district. $V N U$ Journal of Science: Education Research, 32(5E), 90-101.

Nguyen, N. Q., \& Quan, N. M. (2015). Các nhân tố ảnh hưởng đến mức độ hài lòng của người dân đối với cơ chế một cửa liên thông tại quận Thốt Nốt, thành phố Cần Thơ [Factors affecting the level of satisfaction of people with the interconnected OSS mechanism in Thot Not district, Can Tho City]. Tạp chí Khoa học Truờng Đại hoc Cần Tho', 38(2015), 91-97. 
Parasuraman, A., Zeithaml, V. A., \& Berry, L. (1985). A conceptual model of service quality and its implications for future research. Journal of Marketing, 49, 41-50.

Parasuraman, A., Zeithaml, V. A., \& Bitner, L. L. (1988). A multiple-item scale for measuring consumer perceptions of service quality. Journal of Retailing, 64(1), 12-40.

Pham, H. T., \& Le, H. D. (2018). Các nhân tố ảnh hưởng đến sự hài lòng của người dân đối với chất lượng dịch vụ hành chính công trên địa bàn huyện Cẩm Mỹ, tỉnh Đồng Nai [Factors affecting people's satisfaction with the quality of public administrative services in Cam My district, Dong Nai province]. Tạp chi Khoa học và Công nghệ Lâm Nghiệp, 3.

Ramseook-Munhurrun, P., Lukea-Bhiwajee, S. D., \& Naidoo, P. (2010). Service quality in the public service. International Journal of Management and Marketing Research (IJMMR), 3(1), 37-50.

Rodríguez, P. G., Burguete, J. L. V., Vaughan, R., \& Edwards, J. (2009). Quality dimensions in the public sector: Municipal services and citizen's perception. Journal of International Review on Public and Nonprofit Marketing, 6(1), 75-90.

Rust, R. T., \& Oliver, R. L. (1994). Service quality: New directions in theory and practice. Thousand, CA: Sage Publication, Inc.

Schneider, B., \& White, S. S. (2004). Service quality: Research perspectives. Thousand Oaks, CA: Sage Publication.

Wisniewski, M. (2001). Using SERVQUAL to assess customer satisfaction with public sector services. Managing Service Quality, 11(6), 380-388.

Zeithaml, V. A., Bitner, M. J., \& Gremler, D. D. (2009). Service marketing: Integrating customer focus across the firm (5th ed.). New York, NY: McGraw-Hill. 